\title{
SCIENTIFIC INNOVATION FOR THE SUSTAINABLE DEVELOPMENT OF AFRICAN AGRICULTURE
}

\author{
Silvia Travella1,2, Dulce de Oliveira' ${ }^{1,2}$, Sylvie de Buck ${ }^{1,2}$, \\ Fernand Lambein ${ }^{1,2}$, Delphin Diasolua Ngudi, ${ }^{1,2}$, \\ Vanessa De Bauw'1,2, Godelieve Gheysen ${ }^{1,3}$, \\ Marc Van Montagu, ${ }^{1,2}$, Marc Heijde ${ }^{1,2}$ \\ 1 International Plant Biotechnology Outreach, VIB, Belgium \\ 2 Department of Plant Biotechnology and Bioinformatics, Ghent University, Belgium \\ 3 Department of Biotechnology, Faculty of Bioscience Engineering, Ghent University, \\ Belgium
}

\begin{abstract}
The African continent has considerable potential to reap the benefits associated with modern agricultural biotechnology. Plant biotechnology and breeding represent an invaluable toolbox to face the challenges of African agriculture, such as food and nutrition security, environment protection, soi fertility, and crop adaptation to new climatic conditions. As Africa has only relatively recently adopted agricultural biotechnology, it has the opportunity to harness the immense knowledge gathered over the last two decades while avoiding some of the difficulties experienced by early adopters. High-level research and education systems together with a specific regulatory framework are critical elements in the development of sustainable biotechnology-based agriculture and industry. The more actors that are involved in Research \& Development applied to nutritionally and important local crops, the faster Africa will generate its future African innovators. Here, we discuss the contribution of plant biotechnology to a transformative African agriculture that combines intensification of land productivity and environmental sustainability.
\end{abstract}

KEY WORDS: PLANT BIOTECHNOLOGY, AFRICA, YIELD POTENTIAL, NUTRITION SECURITY, ENVIRONMENTAL MITIGATION

\section{Introduction}

The African economy is driven by agriculture, a sector that is the primary employer in many countries, particularly in the most populated rural areas. Between 20II and 20r6, on average $51 \%$ of employment was in agriculture (African Development Bank, 2018). The vast majority of the farmers are principally subsistence farmers trapped in hunger and poverty with average farm sizes of 2 hectares or less. The African continent holds large amounts of natural resources, ranging from mineral deposits, water and oil reserves to forests and farmland. More than $60 \%$ of the arable land is unexplored, reflecting its untapped agricultural potential. Africa also has a high level of human capital, with a population of more than $\mathrm{I} .2$ billion people (ffiI $7 \%$ of the total world population) distributed over 54 different nations ( 55 with the Occidental Sahara). Projections indicate 
that by 2050, global food demand will increase by at least $60 \%$ above $2005 / 2007$ levels (FAO et al., 2018), an increase driven by population growth and rising income levels together with changes in food habits and migration of rural populations to cities (Joint Research Centre, 2017). Sub-Saharan Africa (SSA) is the region at greatest risk of food insecurity because by 2050 its population will have increased 2.5 -fold (ffiup to more than $40 \%$ of the total world population) and, for instance, the demand for cereals is expected to triple (FAO et al., 20I8).

The rapid growth of the African population and the adverse effects of climatic change put increasing pressure on land availability, land fertility, and water access, and present a growing threat to food security, ecosystem management, and inequalities (e.g. between better-off and poorer farmers, women and men, urban and rural populations, etc.) (Franks et al., 20I7). Furthermore, the gap is expanding between regional demand and supply and between regional supply and global demand. For instance, cassava (Manihot esculenta) production in Ivory Coast (Coulibaly et al., 20I4) and cocoa (Theobroma cacao) production in Ghana (Wessel and Quist-Wessel, 2015) cannot meet the demand in West Africa. Today, African agricultural productivity is much lower than in Europe, North and South America, or Asia. Indeed, according to the Food and Agricultural Organization (FAO) statistics (http://www.fao.org/faostat/en/\#data), in 2016 the yield of maize (Zea mays) cultivation reached Io.9 tons/ha in the USA, whereas the average yield was only I.9 tons/ha in Africa. This disparity in yield not only holds true for maize, but also for other crops, such as banana (Musa sp.), cassava, cowpea (Vigna unguiculata), rice (Oryza sativa), and sorghum (Sorghum bicolor). Such underperformance constitutes a poverty trap, keeps rural incomes low, and food prices high, thus reducing the potential of the agricultural sector to attract future generations. Consequently, most African countries are still net importers of food. The situation is symptomatic of severe and long-term underinvestment in African food and agricultural systems. Moreover, several factors have hampered the potential of the agricultural sector to grow and develop, including a widening technological gap, weak infrastructure for collection, transportation, storage of harvests, and poor technical capacities to fight against the wide range of pests and diseases favored by climatic conditions. These challenges have been exacerbated by political instability and lack of investment in agricultural research and education, but also by governance matters, such as access to land and rights issues, limited access to affordable credit, and low availability to high-quality products, such as seeds, fertilizers, and pesticides, among others (Kanu et al., 20I4).

It has become increasingly evident that there is a need to reinvest in African agriculture with all available tools and support. In 2017, African governments recognized the crucial role of agriculture and the related agri-food sector in stimulating inclusive economic growth and development and in alleviating poverty (African Green Revolution Forum, 20I7). The Science, Technology and Innovation Strategy for Africa (STISA 2024) has been designed as a medium-term strategy towards the continental developmental goals established by the African Union Agenda 2063. The Science Agenda for Agriculture in Africa $\left(\mathrm{S}_{3} \mathrm{~A}\right)$ fosters the implementation of the Comprehensive Africa Agriculture Development 
Programme (CAADP). Both STISA 2024 and S3A realize how important science and technology are to bringing about a productive and efficient food and agricultural sector in the continent, delivering economic growth, wealth creation, food and nutrition security as well as political stability. This is a consolidation of the aspirations of diverse actors in the agricultural sector including policy makers, private sector organizations, producer associations/organizations, research institutions, and academia. To achieve the ambitious goals of transforming Africa's economy and agriculture through the deployment of science and innovation, strong South-South and North-South cooperation will be needed. The development of the agri-food sector is crucial for a sustainable food system that will enable Africa to reduce the "multiple burden of food insecurity and malnutrition". Although there has been worldwide progress in reducing hunger and all forms of malnutrition within the framework of the Sustainable Development Goals (SDGs), undernutrition and nutrient deficiencies persist in Africa and have even increased in 2018 for the third year in a row, affecting almost $2 \mathrm{I} \%$ of the population, i.e. more than 256 million people (FAO et al., 2018). Dealing with food security from a production angle alone has not worked thus far. Indeed, food production can become sustainable only as part of a sustainable food system that includes balanced food consumption and diets, reduced food waste, and improved access to sufficient, diverse, safe, and high-quality nutritious food for all. Diversification can prevent socio-economic diseases such as konzo that is associated with ingestion of the carbohydrate-rich roots of cassava that contain residual cyanogens. Such a sustainable food system should also address issues related to postharvests as well as to processing and packaging technologies to diminish supply fluctuations throughout the year. The food processing and manufacturing industry offers great hope to African countries that need to increase employment. Therefore, the private agro-industry has a role to play in revitalizing African agriculture and food systems and in developing a vibrant agri-food sector. To ensure production efficiency, the capacity of the African agri-business needs to be further built up with improved and appropriate technologies, knowledge, and skills. Consequently, this will improve food and nutrition security, develop a sustainable agriculture, and create jobs, triggering positive migration with more exchanges between, for instance, the European and the African food industries, and, finally, alleviating poverty. Africa is the world's most youthful continent. In 2015, 60\% of the African population was under 25 years old (Mo Ibrahim Foundation, 20I7). To fulfill national, regional, continental and global value chains, education, youth employment and access to high-quality jobs should be encouraged as a means to promote inclusive and sustainable economic prosperity, especially in rural farming communities. The aim ofInternational Plant Biotechnology Outreach (IPBO), a unit within VIB, a biotechnological institute of Flanders, is to build bridges between Flemish scientists and African stakeholders in order to share research capacity, knowledge, and technologies. The group's activities are based on three main interconnected pillars, namely communication, capacity building, and project development for a sustainable and intensified agriculture and agro-industry in Africa (http://www.ipbo.vib-ugent.be). Over the years, IPBO has become an expert in creating awareness around plant biotechnology tools and their 
potential impact on society and the environment, with a special focus on Africa. In this context, IPBO strongly supports the use of all available tools and scientific knowledge to meet the SDGs defined by the United Nations. Academic research is fundamental to ensuring progress, particularly in agricultural research, so as to meet the food demands of a fast-growing and developing global population. In particular, plant biotechnology can play an important role in tackling challenges related to agricultural production and climatic resilience, particularly in the regions of greatest need. By stimulating research on the improvement of crops that are relevant for African countries, IPBO helps to increase the potential societal impact of scientific innovation in the field of plant biotechnology. Here, we discuss the contribution of plant biotechnology for the African agricultural transformation that combines intensification of land productivity with environmental sustainability.

\section{Plant biotechnology}

It is widely recognized that modern technologies will play a critical role in the transformation of African agriculture (Blanke and Fregene, 2018). Emerging and future digital technologies, such as precision farming and autonomous agricultural equipment will probably enhance agricultural productivity and sustainability. Another important aspect is improvement of germplasm with desirable traits, and biotechnology is a major source of germplasm innovation. The wide range of plant biotechnology tools - micropropagation-based tissue culture, interspecific and intergeneric hybridization, marker-assisted selection, biopesticides and biofertilizers, artificial seed production, genetic modification and, most recently, precision genome engineering technology - complement conventional plant breeding and well-managed agronomic practices and provide a quantum leap in sustainable agriculture (Singh et al., 2018). These "green biotechnologies" represent an invaluable toolbox to face the challenges of today's agriculture in Africa, which are food and nutrition security, environment protection, soil fertility, and crop adaptation to new climatic conditions.

Genetic modification is the technology that has already enabled a big jump forward in new trait discovery and development. There has been a rapid uptake of genetically modified (GM) crops since their first commercialization in 1996. By 2017, GM crops were grown globally by more than I8 million farmers on $\mathrm{I} 89.8$ million hectares of land. This area is equivalent to almost $20 \%$ of the total land area of China or the USA and more than 7 times the land area of the United Kingdom (ISAAA, 2017). In the literature, the significantly positive socio-economic and environmental impact of two decades of commercialization of GM germplasm (Klümper and Qaim, 20I4; Brookes and Barfoot, 2017a, 2017 b) has been reported extensively. Indeed, GM maize was shown to provide a double benefit: a reduced impact on the environment and a concrete positive effect on human and livestock health. For instance, GM maize varieties with decreased insect crop damage are less susceptible to Fusarium verticillioides infection and, therefore, have reduced fumonisin content (Pellegrino et al., 20r8).

While such achievements are impressive, GM technology is far from reaching its full po- 
tential. Only a few dozen GM crops are available today, four of which - soybean (Glycine max), maize, cotton (Gossypium hirsutum) and canola - and only two traits - herbicide tolerance (HT) and insect resistance (IR) - covered approximately $99 \%$ of the global GM crop area in 2017 (ISAAA, 2017). As the transfer of GM crops from laboratory to field cultivation requires a tremendous investment of time and resources, the development of GM traits has traditionally been reserved to a few major companies. The high development costs and the linked regulatory expenses can only be recouped for these few major crops that are globally economically important and that represent large seed markets. For instance, the costs of discovery, development, and legal authorization of a single new plant biotechnology trait introduced between 2008-2012 was approximately 136 million USD. Regulatory science, registration, and regulatory affairs are the most time-consuming single phase in product development and are estimated to account for $26 \%$ and $37 \%$ of the total price and time involved, respectively (McDougall, 20II).

Nevertheless, GM crops have steadily being adopted year on year since the gos. Although in Africa, only South Africa (IR/HT cotton, IR/HT maize, and IR/HT soybean) and Sudan (IR cotton) commercially grew GM crops in 2017, the proportion of GM products with different traits of agronomic interest in the commercialization pipeline is higher in Africa than that of the traditional high-tech agricultural regions, such as the USA and Europe (Parisi et al., 20I6). Currently, I2 GM crops are cultivated in I3 African countries and I4 traits are under different stages of research, field trials, and commercialization (Table I) (ISAAA, 20I7). Moreover, an increasing number of research studies and field trials are being performed on so-called "orphan crops", which are mainly traditional African food crops with a potentially high importance at national or regional levels (e.g., cassava, cowpea, and sorghum), but less relevant for international trade. Furthermore, various African governments strongly endorse the technological benefits through increased expression of political goodwill and budget allocations: Ethiopian Government Banking on Agri-biotech to Help Steer Economic Development (http://www.isaaa.org/kc/cropbiotechupdate/ article/default.asp?ID=16959); Biotech Has Huge Potential to Transform Uganda's Growth, Minister Says (http://www.isaaa.org/kc/cropbiotechupdate/article/default.asp?ID=16886); Kenyan Policy Makers Vouch for Commercialization of Bt Cotton (http://www.isaaa.org/kc/cropbiotechupdate/article/default.asp?ID=16864); African Governments Must Prioritize Agriculture to Drive Inclusive Economic Growth and Development (https://www.africa-newsroom.com/press/ african-governments-must-prioritize-agriculture-to-drive-inclusive-economic-growthand-development).

New powerful tools are now available for plant amelioration and will greatly facilitate the engineering of complex traits, such as disease tolerance, insect resistance, yield improvement, productivity stability, resilience to abiotic stresses, and nutritional food quality (Zhang et al., 20I7a). One such novel tool of genome (or gene) editing is the clustered regularly interspaced short palindromic repeats/CRISPR-associated protein 9 (CRISPR/ Cas9) system that harnesses the potential of release permanent and desirable targeted changes in an organism (Doudna and Charpentier, 20I4). This new technology together with other gene editing techniques allows the addition, removal, or alteration of genetic 


\begin{tabular}{|c|c|c|}
\hline Crop & Country & Traits \\
\hline Banana & Uganda, Malawi, Kenya & $\begin{array}{l}\text { Biofortified vitamin A } \\
\text { Black leaf sigatoka fungus resistance } \\
\text { Banana bacterial-Xanthomonas wilt resistance } \\
\text { Nematode resistance }\end{array}$ \\
\hline Banana plantain & Malawi, Uganda & $\begin{array}{l}\text { Bunchy top virus resistance } \\
\text { Nematode resistance }\end{array}$ \\
\hline Cassava & Kenya, Nigeria, Uganda & $\begin{array}{l}\text { Cassava virus mosaic disease resistance } \\
\text { Cassava virus brown streak disease resistance } \\
\text { Delayed postharvest starch deterioration }\end{array}$ \\
\hline Cowpea & $\begin{array}{l}\text { Burkina Faso, Ghana, Malawi, } \\
\text { Nigeria }\end{array}$ & Insect (Maruca pod borer) resistance IR \\
\hline Cotton & Ethiopia, Kenya, Nigeria, Swaziland & Insect (bollworm) resistance IR \\
\hline $\begin{array}{l}\text { Gypsophila } \\
\text { flower }\end{array}$ & Kenya & Pink coloration of petals \\
\hline Maize & $\begin{array}{l}\text { Kenya, Mozambique, Tanzania, } \\
\text { South Africa, Uganda, Nigeria }\end{array}$ & $\begin{array}{l}\text { Insect (bollworm) resistance (IR) } \\
\text { Drought tolerance (DT) } \\
\text { Stacked IR/DT }\end{array}$ \\
\hline Potato & Uganda & Late blight resistance \\
\hline Rice & $\begin{array}{l}\text { Burkina Faso, Ghana, Nigeria, } \\
\text { Uganda }\end{array}$ & $\begin{array}{l}\text { Nitrogen Use Efficiency } \\
\text { Water Use Efficiency }\end{array}$ \\
\hline Sorghum & Kenya, Nigeria & Biofortified vitamin A \\
\hline Sweet potato & Kenya & Virus disease resistance \\
\hline Soybean & South Africa & $\begin{array}{l}\text { Herbicide tolerance stacked with a modified } \\
\text { fatty acid profile }\end{array}$ \\
\hline
\end{tabular}

Source: adapted from ISAAA (2017).

Table 1: Crop traits under various research stages in Africa by 2017

material at preselected locations in the genome with a level of precision never reached before. As such, it has the potential to revolutionize the agricultural and breeding sectors in the near future. Furthermore, with these techniques, the function of one or more specific genes can be disrupted, existing sequences can be edited to reproduce ancient alleles, and new beneficial alleles or new genetic material can be introduced (Rani et al., 2016). Thanks to the ability to simultaneously target multiple genomic loci and to modulate the gene expression, these new breeding techniques are a more viable approach for inserting resistance genes into plants and for knocking-out whole gene families (Lowder et al., 20I5). Food security-improving traits have been obtained by genome editing techniques; for instance, mutation of disease susceptibility genes (S genes) has resulted in powdery mildew (Blumeria graminis) resistance in bread wheat (Triticum aestivum L.) (Zhang et al., 20I7b) and in a broad potyvirus resistance in cucumber (Cucumis sativus L.) (Chandrasekaran et al., 2016); rice was made resistant to certain pathotypes of bacterial leaf blight (Xanthomonas oryzae) (Zhou et al., 2015). The deletion of genes involved in starch biosynthesis produced high amylopectin ("waxy") maize (van de Wiel et al., 20I7) and potato 
varieties (Andersson et al., 20I6). Knockouts in genes involved in further steps in the fatty acid biosynthesis increased the oleic acid concentration in oilseed soybean (Haun et al., 20I4) and false flax (Camelina sativa) (Jiang et al., 20I7). The first industrial true gene-edited food -the Calyxt's "healthier" soybean - went on the US market for cultivation in 2018 (http://www.calyxt.com/products/high-oleic-soybean/).

Precision genome engineering approaches are by far more accurate, efficient, and rapid when compared to earlier techniques of crop improvement, such as induced mutagenesis and genetic modification (Rani et al., 20I6). The genome-editing applications that do not aim at the insertion of foreign genes, but at the induction of site-specific mutations in a plant's own genetic material, generate organisms that could have existed naturally or through traditional breeding methods. Although precise genome editing is recognized as a revolutionary plant breeding technique, it is still restricted to plant species that are easily transformed and are genetically simple, such as maize.

To become major game changers in the development of more efficient crops in Africa, gene-editing techniques necessitate optimal genomic information and transformation methods (stable or transient), requirements that are lacking for most crops important to African diets. The African Orphan Crops Consortium (AOCC) initiative will probably partially mitigate the difficulties ahead. The main goal of the AOCC is to sequence, assemble, and annotate the genomes of Ior traditional African crops, many of which are rich in vitamins, micronutrients, antioxidants, and medicinal ingredients (http://africanorphancrops.org/). These Ior crops have been selected by a diverse panel of African scientists, anthropologists, food scientists, nutritionists, plant breeders, farmers, and sociologists along with various other stakeholders according to certain criteria, such as nutritional value, widespread use, unsequenced, climatic adaptability, and drought and pest resistance. Most orphan crops represent the basic food system in rural Africa, they are nutritionally and economically important as well as socio-culturally relevant, e.g., drumstick tree (Moringa oleifera), finger millet (Eleusine coracana), yams (Dioscorea sp.), and fonio (Digitaria sp.). The AOCC also aims at training African plant breeders to use the latest strategies and technologies in plant breeding and to produce crops that are more nutritious, have improved yields, and can withstand the effect of climate change.

\section{Reducing the yield gap}

Most SSA countries record huge differences between actual and projected crop yields (Epule et al., 2018). The agricultural activities are largely at subsistence levels, not strongly linked to industrial growth and increased markets, and dependent on both climatic and non-climatic factors. The impact of climate change on the African continent is predicted to be severe, especially because African agriculture is $95 \%$ rain-fed. Climatic variability with extreme weather events, such as droughts, floods, and extreme temperatures (heat and frosts), have a high impact on crop yield and qualities. Non-climatic drivers of low productivity include limited access to and utilization of sufficient external inputs, including irrigation, machines, certified seeds, fertilizers, pesticides, and unsustainable cultivation methods, such as slash-and-burn cultivation and deforestation for farmland 
expansion and wood fuel gathering, that lead to nutrient mining, soil erosion, and degraded lands (Epule et al., 20r8). The underlying causes of the poor productivity in African agriculture are, therefore, diverse, but the challenges faced by small-scale farmers are mainly lack of capital and opportunities to invest in agricultural inputs, adequate technologies, and quality-improved seeds. The circulation of counterfeit seeds is a major problem in Africa and hinders the transformation of its agricultural sector. Thus, on the one hand, a well-functioning, market-driven high-quality seed system is necessary to monitor and eliminate counterfeit seeds and, on the other hand, research scientists need to work more closely with small-scale farmers to improve seed quality.

To meet the challenge of climatic variability, two major initiatives have been undertaken with the aim of reducing the effects of drought stress in maize, a major food crop in Africa. The firstwas the Drought-Tolerant Maize for Africa (DTMA) project implemented by the Centre for International Maize and Wheat Improvement (CIMMYT) and the International Institute for Tropical Agriculture (IITA) and ended in 2015 (http://dtma.cimmyt.org/index.php/about/background). The objective of the second initiative, the WaterEfficient Maize for Africa (WEMA) project, is to develop new maize varieties resistant to moderate drought and insect-pest protected. In this public-private partnership, the associated company provides the GM technology free of royalties and the public partner provides the high-yielding maize varieties adapted to the African environment. The project tested varieties through field trials in several countries over the African continent (De Buck, 20I7) and in 2018 has concluded its first decade of research. The WEMA project has developed conventional drought-resistant maize hybrids, which are sold under the brand name DroughtTEGO, as well as GM varieties, to be marketed under the brand name TELA, that offer both drought tolerance and insect resistance.

The productivity constraints must be assessed with all available tools and supports, including plant biotechnology, breeding, and, importantly, adapted agricultural development policies. Genotype x environment interactions are of paramount importance. Plant biotechnology and breeding play an important role in the enhancement not only of the nutritional quality, but also in the adaptation, resistance, and resilience to yield-affecting abiotic and biotic stresses. Yet, local food habits, markets, and traditions also highly influence the choice of African small-scale farmers to grow cultivars. For instance, although the yield of some local maize varieties cultivated in Kenya is poor when compared with current tropical hybrids, their early maturity is very much appreciated because the green cobs can be harvested for roasting during food scarcity (Tittonell and Giller, 20I3). Plant breeding programs are required that utilize all the tools available, including use of hybrids, as well as GM and gene-edited crops, that fit in good agricultural practices and intercropping.

One of the major limitations to plant breeding in Africa is that research on most of Africa's indigenous crops, such as sorghum, millet, cassava, yam, teff (Eragrostis tef), bambara ground nut (Vigna subterranea), marama bean (Tylosema esculentum), chickpea (Cicer arietinum), grass pea (Lathyrus sativus), and cowpea, has been neglected and underfunded, because these orphan crops have indeed a limited importance on the global market, 
whereas through policy support, research, product elaboration, or development aid, the major investments still focus today on the globally important crops, rice, wheat, and maize. The dependence of Africa on these major crops is disconcerting considering that Africa has its own local traditional crops. Furthermore, these neglected, but locally significant, crop species are characterized by high resilience, adaptation to environmental stresses and are well suited to African marginal environments. Wherever they are locally produced and utilized, these orphan crops provide an indispensable source of staple food to the vast majority of the resource-poor and low-income farming societies and, hence, can help to ensure food and nutrition security. They are uniquely adapted to their local environments and play a vital role in supporting more diverse diets with a better supply of particular nutrients, i.e. essential amino acids, fibers, and proteins. With today's technological developments, research could offer an opportunity to improve the productivity and the nutritional value of these orphan crops. The number of initiatives is increasing for some of these crops (Table I). A leading example of a legume crop is cowpea. Cowpea is grown on more than Io million hectares in West and Central Africa with Niger being the largest producer with 5 million hectares in 2016 (http://www.fao.org/faostat/ en/\#data). Still the demand is higher than the production. Producers are faced with yield losses due to the Maruca pod borer. Therefore, the creation of an insect-resistant cowpea variety has been undertaken by a private/public partnership funded by the United States Agency for International Development (USAID). Moreover, the IITA is developing banana plants resistant to either bacterial wilt or nematodes. Diseases, such as bacterial wilt, are able to destroy a whole plantation, for instance more than $70 \%$ of the production was lost in Uganda in 2015 (Nkuba et al., 2015). Very recently, by screening the entire banana collection at the IITA, I 3 banana varieties have been identified that are resistant to the bacterial banana wilt disease (Nakato et al., 20I8). Until then, because no resistance source in banana germplasm had been detected, the only direct alternative solutions were to genetically modify banana with resistance genes identified in sweet pepper (Capsicum annuum) (Tripathi et al., 2017).

From 2016 until today, cereal farmers across SSA experience heavy yield losses that threaten food security and trade, due to the devastation by a new alien invasive pest, the fall armyworm (Spodoptera frugiperda). Damage to maize alone is estimated to be between 2.5 to 6.2 billion USD per year (Prasanna, 20I8). This caterpillar is native to tropical and subtropical regions of the Americas and its common name, fall armyworm, is based on its mass invasions in search of warmer climates throughout the fall (autumn). The larvae are most damaging and can destroy maize farms overnight, but the adult moths ensure the rapid spread of the pest. Moths are very strong fliers, covering vast distances every week, up to Ioo $\mathrm{km}$ a day. As the major challenge is to control the outbursts of larvae, the emergency responses of the affected countries have been to use pesticides that in most cases have proven costly and not very effective. To control the fall armyworm in Africa, integrated pest management is needed to suppress pest populations and maintain them below economic loss-causing levels. All available methods can be combined, such as early warning systems, habitat management with the push-pull systems, introduction 
of a trap crop in the field, application of sand or ash into the plant whorl, host plant resistance, Bacillus thuringiensis (Bt) maize GM technology, biological control with the introduction of natural enemies, and chemical control, where timing of the insecticide application is critical for high efficiency (Prasanna, 20I8).

\section{Consumer-beneficial crops}

Thus far, GM traits commercialized worldwide have mainly been oriented toward farmers' needs (e.g. HT and IR). Today, it seems that both private and public initiatives increasingly carry out research to develop consumer-beneficial crops in addition to HT and IR traits. In 2015, the United Nations Food and Agriculture Organization estimated that approximately 792.5 million people in the world were malnourished, of which 780 million lived in food-insecure countries. In addition, approximately two billion people across the world suffer from another type of hunger, known as "hidden hunger", which is caused by an inadequate intake of essential micronutrients and vitamins in the daily diet, in spite of increased food crop production, namely vitamin A, iron, zinc, calcium, manganese, copper, iodine, or selenium (FAO et al., 2018).

To prevent the "hidden hunger" or "micronutrient malnutrition" and to produce nutrient-rich food crops in sufficient quantities, crops can be generated by conventional plant breeding and, much faster, by modern biotechnology techniques that are biofortified or "nutritionally enhanced" in vitamins, minerals, essential amino acids, and essential fatty acids, potentially improving the lives of millions of people who have limited access to well-balanced diets (Garg et al., 2018). These products might not always be relevant for the global industrial sector, but might theoretically have a high impact on developing regions and be beneficial to small-holder farmers and consumers.

The HarvestPlus programme (http://www.harvestplus.org/) that was set up to breed biofortified staple food crops by conventional breeding, invests a lot to boost three key nutrients, namely vitamin A, iron, and zinc. It targets the staple crops wheat, rice, maize, cassava, pearl millet, bean (Phaseolus sp.), and sweet potato (Ipomoea batatas) in Africa and Asia. For instance, the dominant sweet potato varieties in SSA are white-fleshed, deficient in $\beta$-carotene. The vitamin A-enriched orange-fleshed sweet potato consumption had a significant effect on the household food and nutritional security in the SSA countries. For this contribution, HarvestPlus and the plant breeders of the SASHA project (Sweetpotato Action for Security and Health in Africa) were honored with the World Food Prize 2016. Biofortification by breeding is carried out in crops when genetic diversity in the nutrient content is available in the gene pool of the targeted crop. Other examples of biofortified varieties released in Africa are vitamin A-rich banana (Burundi), cassava (Nigeria), and maize (Zambia, Nigeria, and Ghana); iron-rich sorghum (Nigeria); high lysine and tryptophan maize (South Africa, Ghana, Benin, Uganda, and Mozambique) (reviewed by Garg et al., 20I8). When genetic diversity is limited or unavailable, biotechnological approaches are a good alternative. The best-known example of a biofortified GM crop is Golden Rice. This humanitarian project was developed to counteract the vitamin A deficiency in the diets of the poorest and that affects the children's health in regions 
where rice is a major staple food. Similarly, the genetically enriched, golden-colored banana may help prevent blindness caused by vitamin A deficiency in Uganda for children whose diets lack this nutrient (Paul et al., 20I8). Different GM cassava varieties biofortified for enhanced levels of iron, $\beta$-carotene, and zinc are under development and field trials in the Biocassava Plus $(\mathrm{BC}+$ ) program are targeted to African countries (Sayre et al., 20II). Similar strategies are employed with success in different food crops as well as in cereals, legumes, vegetables, oilseeds, fruits, and fodder crops, e.g., soybean with high unsaturated fatty acid, soybean enriched in cysteine and methionine, sorghum with improved storage protein digestibility, and potato (Solanum tuberosum) with high starch content (reviewed by Garg et al., 20I8). It is important to note that today, biofortified GM crops have only been approved in industrialized countries, such as Golden Rice, oleic acid-rich soybean, high-starch quality potato for food and animal feed, and Phytaseed ${ }^{\mathrm{TM}}$ canola with increased available phosphorus for monogastric animals. None have entered the commercialization phase in developing countries, where they are needed most of all (Garg et al., 20I8) and where such absence keeps protracting human suffering especially child blindness.

Additionally, mycotoxins are major food contaminants that affect global food safety and security, especially in low- and middle-income countries and in particular in SSA. Mycotoxins are naturally occurring toxic chemicals produced by fungi that infect agricultural crops (mainly cereals and groundnuts) during growth, inadequate drying, and subsequent storage. When eaten, these infected crops have noxious effects on humans and animals (i.e. mycotoxicosis) and, particularly aflatoxins can be traced back to milk products and to urine samples of young children. Therefore, mycotoxins not only have a deleterious health impact, but also reduce the amount of available food/feed and adversely affect the worldwide trade of Africa (Ssepuuya et al., 20I8; https://mytoxsouth.org/). To fight against mycotoxins, a coherent pre- and post-harvest management system must be established and applied to ensure safety at all levels in the crop production chain. Programs should be implemented to improve good agricultural practices along the production chain, through transport, storage, and final distribution. In the case of peanut (Arachis hypogaea), post-harvest management practices, such as appropriate drying and storage, can effectively minimize aflatoxin contamination only when peanuts are free from pre-harvest infection. The recent development of aflatoxin near-immune peanuts through GM techniques has offered a panacea for serious food safety, health, and trade issues in SSA and in South Asia (Sharma et al., 2018).

\section{Biosafety regulation}

As the African continent has been rather late to adopt modern biotechnology, it has now has the opportunity to utilize the knowledge gathered over the last two decades without encountering the original difficulties. The use of GM technology-based products has to be controlled by an efficient regulatory framework. Regulatory reviews and approvals for field trials, cultivation, consumption, and the import of GM crops are specific to each country. Most African countries have ratified the Cartagena Protocol on Biosafety and 
are enforced to establish national biosafety legislation. To this end, many countries use the African model law on safety in biotechnology provided by the African Union in 2007. The model serves as a base and needs to be adapted to each national legislation to allow proper regulation.

The implementation of the regulatory framework for biotechnology is far from being uniform in the African continent. In 20I7, I3 African countries (Burkina Faso, Cameroon, Ethiopia, Ghana, Kenya, Malawi, Mozambique, Nigeria, South Africa, Sudan, Swaziland, Tanzania, and Uganda) had a regulatory framework that they implement through various activities from trial evaluations, approval grants for the general release of GM crops to even commercialization and cultivation (in South Africa and Sudan). Ten countries (Algeria, Botswana, Madagascar, Mali, Namibia, Niger, Senegal, Togo, Tunisia, and Zambia) have a law in place that has not yet been applied through field trials or other activities (ISAAA, 20I7). Several countries with a biosafety law in place need a capacity-building effort to strengthen the responsible governmental bodies for better implementation of biosafety programs (Adenle et al., 20I8; Fernández Ríos et al., 2018). Indeed, the implementation of a functional biosafety system requires consultation with applicants, expertise to perform science-based risk assessment, risk management, and fast-tracking procedures. Above all, clear policy objectives and political will are required to make structured and transparent regulatory decisions to reassure not only the local consumers, but also the regional and international markets (Koch, 20I4).

Current regulatory frameworks in many developed countries, and mainly in Europe, tend to undermine the rational application of GM crops in developing countries mainly because of the lack of agreement as to whether and how both scientific and non-scientific evidence can and should be integrated into regulatory decision-making for GM crops (Adenle et al., 20I8). Different from the risk analysis guidelines of the International Plant Protection Convention, the Codex Alimentarius (Codex), and the World Trade Organization that are based on solid science, the precautionary principle embedded in the United Nations Cartagena Protocol on Biosafety balances scientific evidence with subjective economic, social, and environmental norms (Adenle et al., 20I8). However, thus far, there has been little progress in defining how socio-economics should be used in the Cartagena Protocol. This two decade-old controversy between the USA and the European Union on the application of the precautionary principle to GM regulation has clearly affected the advancement of functional biosafety policies and has limited crop development in many developing countries, especially in Africa. When countries apply different rules, the commodity-exporting country has to comply with both regulations of the exporting and importing countries to succeed in the international trade. Poor decision making (or the lack thereof) within weak national regulatory regimes, the lack of agreements at an international level and a shortfall in clear definitions and interpretations of socio-economic considerations, continue to undermine the effective deployment of GM crops. One major concern is the extension of this regulatory challenge to the new genome-editing approaches. In July 20I8, the European Court of Justice (ECJ) ruled that organisms obtained by gene-editing techniques, such as CRISPR, are subject to the same regulations as ge- 
netically modified organisms (GMOs) (https://curia.europa.eu/jcms/upload/docs/application/pdf/20I8-07/cpr8oriren.pdf), despite the obvious differences, not least of which is the impossibility of distinguishing the effects of some types of genome editing and naturally occurring DNA polymorphisms. Simple edits (without foreign DNA) should be exempted, as is already the case in Argentina, Brazil, Canada, Chile, Israel, Japan, and the USA. Adoption of a precautionary principle against the new gene-editing techniques will prevent humanity from enjoying their applications for sustainable agriculture and more dramatic for the mostly rural African population. Science-based risk assessment models in African countries should be better focused on local agricultural and environmental practices instead of based on a Western model, conceivably encouraging regional harmonization of regulatory frameworks and, ultimately, facilitating the cheaper, quicker, and safer evaluation of local/regional GM crops.

\section{Conclusion}

Plant biotechnology and breeding produce crops that are resistant to pests and diseases and that are highly nutritious and resilient to climate instability, and have less impact on the environment. As such, they are invaluable tools for transforming agriculture making it more sustainable, and it is developing countries, including SSA countries, that will probably be the major beneficiaries.

Progress in science and innovation increasingly occurs through collaboration in which individuals and institutions with complementary skills and expertise come together to realize shared goals. Plant biotechnology is knowledge-resource intensive and needs a critical mass of trained and experienced researchers in different fields, from molecular genetics and the different omics to agronomy, law, and sociology. Most African countries possess a lot of qualified researchers who can meet a wide range of food and nutrition security and environmental challenges. Stimulation of regional and international cooperation will empower existing local scientific and technological capacities in African research institutes, universities, and breeding stations. The more actors involved in R\&D applied to local crops, the faster Africa will build its own reservoir of future African innovators.

As research capacities increase, public-sector institutes and private firms in the African economy will have the potential to develop new GM or non-GM crops adapted to their local socio-economic needs. Research on indigenous crops can have an important impact on African agriculture, although many of the local varieties are abandoned in favor of major crops that are sometimes cultivated even in less suitable areas (Chivenge et al., 20I5). Orphan crops and adapted crop husbandry that are tolerant to fluctuating growing conditions can potentially help to mitigate the impact of climate change on food production and, as such, reduce food and nutrition insecurity, particularly for resource-poor households in SSA. This reality has put orphan crops in the spotlight and, today, they deservedly draw interest from the research community. Research is carried out increasingly by the public sector and public-private partnerships in Africa (Tadele, 2018).

The public perception of GM crops is deceptive compared to the potential benefits of 
the technology. The unwillingness to adopt GM crops could be related to some kind of "sacred value" of food. It is not new, as is nicely illustrated by how coffee already triggered the precautionary principle in the $15^{\text {th }}$ century (Juma, 20I6). Coffee is one of the oldest transformative innovations that led to new production processes, creation of new markets, and novel organizational changes in production and sale. But the debate is still open today: is drinking coffee good or bad? In this specific example and also generally, many parameters of controversy are of a social, cultural, and economic order and, thus, touch moral values that are adamant to scientific arguments. Notwithstanding, it is essential to keep the debate alive by raising awareness of the transformative potential of plant biotechnology to help achieve global agricultural sustainability, so that, when new clearly beneficial products become available, they are accepted as enthusiastically as technologies that deliver improvements to our daily life.

Africa has the potential to feed itself, to eliminate hunger, food insecurity, and malnutrition and to become a major player on the global food markets. A burgeoning youth and farmers with abundant untapped arable land constitute a potentially winning combination for this transformation. The sustainable industrialization of Africa will be possible based on the modern transformation of agriculture, mainly in rural areas, together with the creation of enabling environments, i.e. supportive government policies and leadership, suitable for a sustainable knowledge-based development of African agriculture.

\section{Acknowledgment}

The authors acknowledge the Flemish Interuniversity Council-University Development Cooperation, the Research Foundation-Flanders, Ghent University, the Marc \& Nora Van Montagu Fund, and the Ghent Africa Platform, for their support of the IPBO Conference on "Scientific Innovation for a Sustainable Development of African Agriculture" held in Ghent (Belgium), August 30-3I, 20I8. The authors are grateful to Martine De Cock for critically reading and editing the manuscript.

\section{References}

Adenle, A.A., Morris, E.J., Murphy, D.J., Phillips, P.W.B., Trigo, E., Kearns, P., Li, Y.-H., Quemada, H., Falck-Zepeda, J., Komen, J. (20I8). Rationalizing governance of genetically modified products in developing countries. Nature Biotechnology 36(2), I37-I39.

African Development Bank (2018). African Economic Outlook 20I8. Abdijan, African Development Bank (AfDB), 200 p. [ISBN 978-9938-882-62-9].

African Green Revolution Forum (20I7). Accelerating Africa's Path to Prosperity: Growing Inclusive Economies and Jobs Through Agriculture. Forum Report 2017, (https://agrf.org/wp-content/ uploads/2018/06/2017-AGRF-Report-.pdf).

Andersson, M., Turesson, H., Nicolia, A., Fält, A.-S., Samuelsson, M., \& Hofvander, P. (20r6). Efficient targeted multiallelic mutagenesis in tetraploid potato (Solanum tuberosum) by transient CRISPR-Casg expression in protoplasts. Plant Cell Reports 36(I), II7-I28.

Blanke, J., \& Fregene, M. (20I8). Fulfilling Africa's agriculture potential: The role of technology. In Foresight Africa: Top Priorities for the Continent in 20I8. Washington, DC, The Brookings Institution Africa Growth Initiative, pp. 94-95. 
Brookes, G., \& Barfoot, P. (2017b). Environmental impacts of genetically modified (GM) crop use 1996-2015: Impacts on pesticide use and carbon emissions. GM Crops \& Food 8, II7-I47.

Brookes, G., \& Barfoot, P. (2017a). Farm income and production impacts of using GM crop technology 19962015. GM Crops \& Food 8, I56-I93.

Chandrasekaran, J., Brumin, M., Wolf, D., Leibman, D., Klap, C., Pearlsman, M., Sherman, A., Arazi, T., Gal-On, A. (20I6). Development of broad virus resistance in non-transgenic cucumber using CRISPR/Casg technology. Molecular Plant Pathology I7(7), II40-II53.

Chivenge, P., Mabhaudhi, T., Modi, A.T., \& Mafongoya, P. (2015). The potential role of neglected and underutilised crop species as future crops under water scarce conditions in Sub-Saharan Africa. International Journal of Environmental Research \& Public Health I2(5), 5685-57II.

Coulibaly, O., Arinloye, A.D., Faye, M., \& Abdoulaye, T. (2014). Regional Cassava Value Chains Analysis in West Africa: Case Study of Nigeria. Working Paper September 20I4. Dakar, West and Central African Council for Agricultural Research and Develoment (CORAF/WECARD), 57 p.

De Buck, S. (2017). Maize in Africa. Fact Series. Gent, VIB/International Plant Biotechnology Outreach, $56 \mathrm{p}$.

Doudna, J.A., \& Charpentier, E. (2014). The new frontier of genome engineering with CRISPR-Casg. Science 346(6213), 1258096.

Epule, T.E., Ford, J.D., Lwasa, S., Nabaasa, B., \& Buyinza, A. (2018). The determinants of crop yields in Uganda: what is the role of climatic and non-climatic factors? Agriculture \& Food Security 7, ro.

FAO, IFAD, UNICEF, WFP, \& WHO (20I8). The State of Food Security and Nutrition in The World 2018. Building Climate Resilience for Food Security and Nutrition. Rome, Food and Agriculture Organization of the United Nations, I82 p. [ISBN 978-92-5-I3057I-3].

Fernández Ríos, D., Rubinstein, C., \& Vicién, C. (2018). Capacities for the risk assessment of GMOs: Challenges to build sustainable systems. Frontiers in Bioengineering and Biotechnology, 6(4), 40.

Franks, P., Hou-Jones, X., Fikreyesus, D., Sintayehu, M., Mamuye, S., Danso, E.Y., Meshack, C.K., McNicol, I., van Soesbergen, A. (2017). Reconciling Forest Conservation with Food Production In Sub-Saharan Africa: Case Studies From Ethiopia, Ghana and Tanzania, IIIED Research Report. London, International Institute for Environment and Development (IIED), III p. []ISBN 978-I7843I-470-5].

Garg, M., Sharma, N., Sharma, S., Kapoor, P., Kumar, A., Chunduri, V., Arora, P. (2018). Biofortified crops generated by breeding, agronomy, and transgenic approaches are improving lives of millions of people around the world. Frontiers in Nutrition 5(2), I2.

Haun, W., Coffman, A., Clasen, B.M., Demorest, Z.L., Lowy, A., Ray, E., Retterath, A., Stoddard, T., Juillerat, A., Cedrone, F., Mathis, L., Voytas, D.F., Zhang, F. (2014). Improved soybean oil quality by targeted mutagenesis of the fatty acid desaturase 2 gene family. Plant Biotechnology Journal I2(7), 934940.

ISAAA (2017). Global Status of Commercialized Biotech/GM Crops in 2017: Biotech Crop Adoption Surges as Economic Benefits Accumulate In 22 Years. ISAAA Brief 53, I-I53.

Jiang, W.Z., Henry, I.M., Lynagh, P.G., Comai, L., Cahoon, E.B., \& Weeks, D.P. (2017). Significant enhancement of fatty acid composition in seeds of the allohexaploid, Camelina sativa, using CRISPR/Cas9 gene editing. Plant Biotechnology Journal I5(5), 648-657.

Joint Research Centre (2017). Science for the AU-EU Partnership - Building Knowledge for Sustainable Development. Executive summary. Ispra, European Commision - Directorate for Sustainable Resources, $9 \mathrm{p}$.

Juma, C. (20I6). Innovation and Its Enemies: Why People Resist New Technologies. New York, Oxford University Press; 4I6 p. [ISBN 9780190467036].

Klümper, W., \& Qaim, M. (2014). A meta-analysis of the impacts of genetically modified crops. PLoS ONE 9(II), eIII629.

Kanu, B.S., Salami, A.O., \& Numasawa, K. (2014). Inclusive Growth: An Imperative for African Agriculture. Tunis, African Development Bank (AfDB), 79 p. [ISBN 978-9938-882-23-o]. 
Koch, M. (20I4). Elements of an enabling biosafety and regulatory environment. In Biotechnology in Africa: Emergence, Initiatives and Future, (Science Policy Reports, Vol. 7), F. Wambugu, \& D. Kamanga (Eds.), Cham, Switzerland, Springer International Publishing. pp. 197-205 [ISBN 978-3-3190400I-I].

Lowder, L.G., Zhang, D., Baltes, N.J., Paul III, J.W., Tang, X., Zheng, X., Voytas, D.F., Hsieh, T.-F., Zhang, Y., Qi, Y. (2015). A CRISPR/Casg toolbox for multiplexed plant genome editing and transcriptional regulation. Plant Physiology I69(Io), 97I-985.

McDougall, P. (20II). The Cost and Time Involved in the Discovery, Development and Authorization of a New Plant Biotechnology Derived Trait. A Consultancy Study for Crop Life International. Midlothian, CropLife International, $24 \mathrm{p}$.

Mo Ibrahim Foundation (2017). Africa at a Tipping Point. 2017 Forum Report (ooror935-5129995725e8c4478bcfo49bfcfa24ae.pdf).

Nakato, G.V., Christelová, P., Were, E., Nyine, M., Coutinho, T.A., Doležel, J., Uwimana, B., Swennen, R., Mahuku, G. (2018). Sources of resistance in Musa to Xanthomonas campestris pv. musacearum, the causal agent of banana xanthomonas wilt. Plant Pathology, in press (doi: 10.1111/ppa.12945).

Nkuba, J., Tinzaara, W., Night, G., Niko, N., Jogo, W., Ndyetabula, I., Mukandala, L., Ndayihazamaso, P., Niyongere, C., Gaidashova, S., Rwomushana, I., Opio, F., Karamura, E. (2015). Adverse impact of Banana Xanthomonas Wilt on farmers' livelihoods in Eastern and Central Africa. African Journal of Plant Science 9(7), 279-286.

Parisi, C., Tillie, P., \& Rodríguez-Cerezo, E. (2016). The global pipeline of GM crops out to 2020. Nature Biotechnology 34(I), 3I-36.

Paul, J.-Y., Harding, R., Tushemereirwe, W., \& Dale, J. (2018). Banana21: From gene discovery to deregulated Golden bananas. Frontiers in Plant Science 9(4), 558.

Pellegrino, E., Bedini, S., Nuti, M., \& Ercoli, L. (2018). Impact of genetically engineered maize on agronomic, environmental and toxicological traits: a meta-analysis of 21 years of field data. Scientific Reports 8, $3 \mathrm{II} 3$ [Erratum Scientific Reports 8, 6485].

Prasanna, B.M., Huesing, J.E., Eddy, R., \& Peschke, V.M. (2018). Fall Armyworm In Africa: A Guide For Integrated Pest Management, Ist Ed.. Mexico, CDMX, The International Maize and Wheat Improvement Center (CIMMYT), IIo p.

Rani, R., Yadav, P., Barbadikar, K.M., Baliyan, N., Malhotra, E.V., Singh, B.K., Kumar, A., and Singh, D. (20I6). CRISPR/Casg: a promising way to exploit genetic variation in plants. Biotechnology Letters 38(I2), I99I-2006.

Sayre, R., Beeching, J.R., Cahoon, E.B., Egesi, C., Fauquet, C., Fellman, J., Fregene, M., Gruissem, W., Mallowa, S., Manary, M., Maziya-Dixon, B., Mbanaso, A., Schachtman, D.P., Siritunga, D., Taylor, N., Vanderschuren, H., Zhang, P. (20II). The BioCassava Plus program: Biofortification of cassava for Sub-Saharan Africa. Annual Review of Plant Biology 62, 25I-272.

Sharma, K.K., Pothana, A., Prasad, K., Shah, D., Kaur, J., Bhatnagar, D., Chen, Z.-Y., Raruang, Y., Cary, J.W., Rajasekaran, K., Sudini, H.K., Bhatnagar-Mathur, P. (2018). Peanuts that keep aflatoxin at bay: a threshold that matters. Plant Biotechnology Journal I6(5), I024-I033.

Singh, R.P., Singh, P.K., Gupta, R., \& Singh, R.L. (2018). Biotechnological tools to enhance sustainable agriculture. In Biotechnology for Sustainable Agriculture: Emerging Approaches and Strategies, R.L. Singh, \& S. Mondal (Eds.). Cambridge, Woodhead Publishing, pp. I9-66 [ISBN 978-0-I28I2I60-3].

Ssepuuya, G., Van Poucke, C., Ediage, E.N., Mulholland, C., Tritscher, A., Verger, P., Kenny, M., Bessy, C., De Saeger, S. (2018). Mycotoxin contamination of sorghum and its contribution to human dietary exposure in four sub-Saharan countries. Food Additives \& Contamination: Part A 35(7), I384-1393.

Tadele, Z. (2018). African orphan crops under abiotic stresses: Challenges and opportunities. Scientifica 2018, I45I894.

Tittonell, P., \& Giller, K.E. (2013). When yield gaps are poverty traps: The paradigm of ecological intensification in African smallholder agriculture. Field Crops Research I43, 76-90. 
Tripathi, L., Atkinson, H., Roderick, H., Kubiriba, J., \& Tripathi, J.N. (2017). Genetically engineered bananas resistant to Xanthomonas wilt disease and nematodes. Food and Energy Security 6(2), 37-47.

van de Wiel, C.C.M., Schaart, J.G., Lotz, L.A.P., \& Smulders, M.J.M. (2017). New traits in crops produced by genome editing techniques based on deletions. Plant Biotechnology Reports II(I), I-8.

Wessel, M., \& Quist-Wessel, P.M.F. (2015). Cocoa production in West Africa, a review and analysis of recent developments. NJAS - Wageningen Journal of Life Sciences 74-75, I-7.

Zhang, K., Raboanatahiry, N., Zhu, B., \& Li, M. (2017a). Progress in genome editing technology and its application in plants. Frontiers in Plant Science 8(2), 177.

Zhang, Y., Bai, Y., Wu, G., Zou, S., Chen, Y., Gao, C., Tang, D. (2017b). Simultaneous modification of three homoeologs of TaEDRI by genome editing enhances powdery mildew resistance in wheat. Plant Journal 9I(4), 7I4-724.

Zhou, J., Peng, Z., Long, J., Sosso, D., Liu, B., Eom, J.-S., Huang, S., Liu, S., Cruz, C.V., Frommer, W.B., White, F.F., Yang, B. (2015). Gene targeting by the TAL effector PthX02 reveals cryptic resistance gene for bacterial blight of rice. Plant Journal 82(4), 632-643. 